\author{
Liying Song \\ (corresponding author) \\ Assistant Professor \\ School of Traffic and Transportation \\ Beijing Jiaotong University \\ Beijing, 100044, China \\ TEL: +86 (010) 51683752 \\ FAX: +86 (010) 51688484 \\ E-MAIL: lysong@bjtu.edu.cn
}

\title{
Tom Cherrett
}

Lecturer

Transportation Research Group,

School of Civil Engineering and the Environment,

University of Southampton,

SO17 1BJ, United Kingdom.

TEL: +44 (0)2380594657

FAX: $+44(0) 2380593152$

E-MAIL: tjc3@soton.ac.uk

\section{Fraser McLeod}

Research Fellow

Transportation Research Group,

School of Civil Engineering and the Environment,

University of Southampton,

SO17 1BJ, United Kingdom.

E-MAIL: f.n.mcleod@soton.ac.uk

\section{Wei Guan}

Professor

School of Traffic and Transportation

Beijing Jiaotong University

Beijing, 100044, China

E-MAIL:wguan@bjtu.edu.cn

5145 words +5 Figures +4 Tables $=7395$ words 
Paper submitted for presentation at the $88^{\text {th }}$ Annual Meeting of the Transportation Research Board, and publication in Transportation Research Record 


\section{ABSTRACT}

The impacts of failed first-time home deliveries on additional carrier journeys (repeat deliveries), and customer trips (to retrieve goods from carrier depots) are of increasing concern to e-retailers and have been assessed in this paper. The attended collection/delivery point (CDP) concept is one solution to deal with first-time delivery failures, using a variety of outlets (e.g. convenience stores, petrol stations, post offices) as alternative addresses to receive deliveries.

Using a database of households from across West Sussex in the UK, this paper confirms that certain benefits might accrue from using networks of Local Collect post offices, supermarkets and railway stations as CDPs, compared with the traditional delivery method where the carrier may make several redelivery attempts to the home with the customer making a personal trip to the carrier's depot in the event that these attempts also fail. A network of CDPs across West Sussex would function most effectively (in terms of reducing the overall travelling costs associated with handing failed first-time deliveries) when:

- The proportion of first-time home delivery failures is over $20 \%$;

- The proportion of customers travelling to the depot is over 30\%;

- $\quad$ Local Collect post offices are used as CDPs;

- $\quad$ Significant numbers of people would walk to their local CDP.

Customers benefit the most from CDPs, with reductions in their current travelling costs of up to $90 \%$ being modelled here. The reduction in carrier travelling costs is much less, but the processing costs associated with home delivery failures are reduced significantly by diverting the failed packages to CDPs. 


\section{INTRODUCTION}

Shopping from home, or from work, is on the increase as more retailers provide on-line shopping facilities. In the United Kingdom, the domestic home delivery market was valued at approximately $£ 58$ billion ( $\$ 86$ billion $^{1}$ ) in 2006 , over $65 \%$ up on 2003 (1). By 2011 , the typical spend of a UK online shopper is estimated to grow to $£ 1,056$ (\$1567) per annum, up from $£ 606$ (\$899) in 2005 (2). Internet shopping transactions are even more pronounced over the Christmas period with an estimated $£ 13.8$ billion ( $\$ 20.5$ billion) being spent online in the UK during Christmas 2007, up from $£ 3.3$ billion ( $\$ 4.9$ billion) during the same period in 2004 (3).

Increases in home delivery activity have heightened concerns over freight traffic in often unsuitable residential areas. The Department for Transport has estimated that there will be a 19-20\% increase in light goods vehicle (LGV) traffic (vans) by 2010 against a backdrop of car traffic increasing by between 15 and $22 \%$ and large goods vehicles by between 5\% and 6\% compared to 2004 (4). Research has suggested that $\mathrm{CO}_{2}$ emissions by road transport in the UK have increased by $8 \%$ since 1990 and although the growth in vans and large goods vehicles only accounted for $29 \%$ of the total growth in vehicle-kilometers, they have collectively accounted for over $97 \%$ of the increase in road-transport $\mathrm{CO}_{2}$ emissions over the same period (5).

The increases in delivery vehicle activity have raised concerns over the number of logistics providers operating 'less-than-truck-load' vehicles $(6,7,8)$ and the 'last mile' problem associated with failed first-time delivery attempts, where nobody is at the delivery address to receive the package. There are several variations to the traditional home delivery method but generally, goods are ordered by the customer and delivered to a location of their choosing, using relatively narrow time windows defined by the retailer. If the delivery fails because no-one is at the address to receive the item, the recipient is left a notification card detailing a number of options, typically:

- The item could be left with a neighbour;

- $\quad$ The item could be left somewhere outside the premises (unsecured);

- The item has been returned to the carrier's depot and further instructions are required from the intended recipient. (Under these circumstances, the recipient can request a further redelivery attempt which could be chargeable or could visit the carriers' depot personally to collect the item).

Research has reported rates of failed first-time deliveries between 12\% (9) and $60 \%$ (10) where no delivery time or arrangement had been made with the customer in advance. The reasons for this high failure rate have been largely due to lifestyle changes: the growth in single-person households; flexible working patterns and higher female employment levels, which have resulted in up to half of UK homes being empty between 9 a.m. and 4 p.m. during weekdays (9). Unsecured delivery at the household, often without the householders consent, can result in theft of the product, denial of receipt and

\footnotetext{
${ }^{1}$ The current exchange rate at $14 / 11 / 08$ is $£ 1=\$ 1.484$.
} 
even burglary (11). IMRG (12) estimated that 65 million first-time home deliveries failed in 2006 , costing $£ 682$ million ( $\$ 1,012$ million). This comprised $£ 300$ million $(\$ 445$ million) in direct costs to retailers, $£ 123$ million (\$183 million) to carriers in making redelivery attempts and $£ 259$ million ( $\$ 384$ million) to customers in terms of wasted time, negotiating, arranging and waiting for redeliveries to be made or collecting parcels personally from a carrier's depot.

Failed deliveries are clearly undesirable from all viewpoints: the carrier suffers additional costs in trying to make further attempts to deliver and through call centre operations; the customer is inconvenienced and may have to travel to the carrier's depot personally to collect, and there are environmental costs due to added vehicle trips for all parties. With such a large proportion of failed deliveries, different delivery solutions have emerged, allowing carriers to drop consignments without the need to obtain the final customer's signature. One solution is to deliver packages to secure storage boxes, sometimes fitted as an integral part of the house, or secured to an outer wall, or for communal use in the form of locker banks $(13,14$ and 15). Another solution, which forms the focus of the research in this paper, is for the carrier to take failed deliveries to a local attended 'collection/delivery point' (CDP), which could be a shop, a petrol station or a post office. The customer is left a card, or could in principle be sent an email or a text message, to inform them where to collect their package. This delivery method is now used by Royal Mail and Parcel Force in the UK using post offices as CDPs. Other CDP examples use grocery stores, newsagents and petrol stations as CDPs. Kiala has 5000 CDPs situated across Europe with outlets in the UK, Belgium, Germany, Austria, Spain, The Netherlands, Luxembourg and France while Pickpoint has a network of CDPs across Germany. A similar system using convenience stores operates successfully in Japan (16). A delivery policy which automatically took failed first-time home deliveries to the customer's nearest CDP could benefit all parties and reduce the collective mileage associated with either redelivering or collecting failed consignments.

Using a database of households across West Sussex in the UK and different networks of exiting business establishments as theoretical CDPs, this paper attempts to identify the most effective CDP options, locations, and quantify the transport benefits if they were to be implemented across the county.

\section{OBJECTIVES}

Using data on home delivery transactions from a cross-section of householders in West Sussex (UK):

- Quantify the impacts of failed first-time home deliveries on current carrier and householder trip making behaviour;

- Appraise the transport and environmental benefits of a range of regional CDP networks including railway stations, supermarkets and post offices for more efficient home delivery operations. 


\section{METHODOLOGY}

As part of West Sussex County Council's continuing work to develop sustainable travel solutions for people living and working in the county, a 'home delivery' questionnaire was sent to 1000 households across West Sussex in June 2006, eliciting a 38\% response. This aimed to quantify householders' home shopping activity, their experiences with failed first-time deliveries and their attitudes to the CDP concept. The responses were used to formulate a series of assumptions used in a modeling process which attempted to:

1) Replicate the transport costs (time and distance incurred by the carrier and by customers in delivering or collecting goods) associated with the 'traditional' delivery method where:

- Up to two attempts are made to deliver a package to the customer on successive days

- Packages which are not delivered on either attempt are returned to the carrier's depot

- Individuals collect missed deliveries from the carrier's depot

2) Contrast and compare these costs against the CDP method where:

- Only one attempt is made to deliver a package to the customer

- Packages which are not delivered to the person's home are taken to the customer's nearest CDP on the same day.

- Individuals collect missed deliveries from their local CDP

The traditional delivery method and the CDP method were modelled with the help of a vehicle routing and scheduling package (DPS RouteLogix). In the case of the former, the carrier routes needed to make deliveries between randomly chosen households (including redeliveries for failures on the previous day) were optimised based on the quickest route between the delivery addresses. In the latter, the carrier had to visit relevant CDPs on the round to drop off failed first-time deliveries. These CDPs were taken from existing networks of businesses that operated across West Sussex. An important assumption was that the carrier would visit each CDP not more than once on a round. If there was more than one CDP to visit by a carrier on a particular round then a simple strategy was to visit the CDPs in an optimal sequence after all the delivery attempts had been made in each CDP catchment area. The road distances and journey time traveled between each of the 379 household origins and the various CDPs (based on the quickest route) were calculated using Microsoft MapPoint. Based on the values of time per vehicle (17) and the journey time of carrier and householder, the transport costs accrued by various home delivery methods were quantified.

\section{CDP options in West Sussex}

A series of potential CDP networks were investigated across West Sussex as part of the modeling process. 


\section{CDP Option 1: Tesco Extra stores}

Tesco is the largest grocer in the UK, having a 31\% share of the grocery market in 2006 (18). Given that approximately half of all shopping trips are food related (105 trips per person per year, equivalent to twice a week) and the car was the main mode of travel for nearly two thirds (63\%) of these shopping trips (19), a potential CDP outlet would be large supermarkets. Tesco Extra superstores have long opening hours, large-capacity car parks, are accessible to the major road network and are situated close to major residential conurbations. There were 12 situated across West Sussex at the time of the research with the average distance from the customer sample being $6.5 \mathrm{~km}$ (Figure 1).

\section{Option 2: Supermarkets from ASDA, Morrison, Sainsbury and Waitrose}

To increase the density of CDPs, the second option assumed that supermarkets from four rival chains could all be used as part of a combined CDP scheme in the county. Research has suggested that the average householder lives $1.6 \mathrm{~km}$ away by road from a supermarket or convenience store in the UK (20) offering significant potential for package collection by more sustainable modes of transport. Fifty three supermarkets from the ASDA, Morrison, Sainsbury's and Waitrose chains were used in the modelling process, all offering long opening hours (Figure 1).

\section{Option 3: Post Offices offering the 'Local Collect' service}

The Royal Mail's 'Local Collect' service (www.royalmail.com) allows failed first-time deliveries, returned to the local sorting office, to be re-directed to the householders nearest participating post office for a small fee. The average road distance to a Royal Mail post office in the UK is $0.9 \mathrm{~km}(20)$ with $90 \%$ of householders living within a 15 -minute walk time of one of the 139 outlets in the UK (21). There were 139 post offices offering 'Local Collect' situated across West Sussex at the time of the research with the average distance from the householder sample being $1.2 \mathrm{~km}$ (Figure 2). Despite restricted opening hours compared to supermarkets, the Royal Mail post office network in the UK already operates a CDP scheme offering significant scope for modal shift in package collection away from the car.

\section{Option 4: Railway stations}

Railway stations have been used as CDPs in Europe (www.dhl.de). The Department for Transport has suggested that $6 \%$ of people use rail transport at least once a week in the UK (21) and $44 \%$ of UK residents live within 26 minutes walk of a railway station. Typically with good transport linkages and facilities for storing packages, the 46 railway stations across West Sussex could make ideal CDPs (Figure 2).

An analysis of the householders quickest route distances to each of the CDPs in the four groups indicated that the average householder lived significantly further away from a Tesco Extra store $(6.5 \mathrm{~km})$ and closer to a Local Collect post office $(1.2 \mathrm{~km})$ compared to the nearest railways station $(3.2 \mathrm{~km})$ or combined supermarket chains $(4 \mathrm{~km})$. 


\section{Modelling Assumptions and Parameters}

\section{Proportion of Failed First-time Deliveries}

The respondents were asked to estimate how often they received home deliveries and what proportion arrived when no-one was in to receive them. The results indicated that the average household would receive 17 deliveries per year (excluding postal deliveries) comparable to the findings by Foley et al. (22) and the UK Department of Trade and Industry (23). Sixty percent of the West Sussex respondents stated that they missed 25\% of their deliveries with $21 \%$ stating that over $50 \%$ failed first-time at their homes. First time delivery failure rates varying from $10 \%$ to $50 \%$ were considered, to test the sensitivity of the results and because estimates for this parameter varied widely in the literature. It was also assumed that half of all redeliveries would fail based on estimates provided by a small number of carriers who were contacted as part of a telephone survey. The impacts of high delivery failure rates on vehicle capacity were not considered in this analysis.

\section{Number of Delivery Addresses}

In this research, 200 addresses were randomly selected from amongst the 379 questionnaire respondents. In the traditional delivery methods, it was assumed that all the carrier delivery rounds involved visits to all 200 householder addresses on the first attempt. In terms of redelivery attempts, it was assumed that if $30 \%$ of the 200 first-time deliveries failed, there would be 60 redelivery attempts needed during the vehicle rounds. It was also assumed that $50 \%$ of all redeliveries failed again, hence 30 households would suffer two failed delivery attempts. In this research, four traditional home delivery methods were modeled, defined according to the proportion of people, having suffered two delivery failures, would then decide to collect the items from the carrier's depot.

- TRD1: $10 \%$ of people who had two delivery failures would travel to the carrier's depot to collect;

- TRD2: $30 \%$

- TRD3: $50 \%$

- TRD4: All people who had two delivery failures would travel to the carrier's depot to collect;

Consequently, in this example, all the delivery rounds would involve visits to 260 addresses in TRD4, 290 (some twice) in TRD3, 302 in TRD2 and 314 in TRD1. Those orders were delivered by up to 8 delivery vehicles.

\section{Travelling to the carrier's depot}

The questionnaire asked how often people had travelled to a carrier's depot to collect a package. The responses were never (38\%), rarely (36\%), occasionally $(21 \%)$ and frequently $(4 \%)$. Twenty one percent of the respondents stated that they travelled to a 
carrier's depot to collect their goods between 3 and 11 times over the past year, the majority of trips $(87 \%)$ being made by car. The main carrier the questionnaire respondents had encountered was Parcelforce, whose depot was on average $37 \mathrm{~km}$ away from each householder origin point. A range of proportions of householders collecting from the carrier's depot were modeled for the traditional delivery method, varying from $10 \%$ to $50 \%$.

\section{Potential use of local CDPs}

The questionnaire results suggested that $46 \%$ of the respondents would nominate their local post office as the most convenient CDP location with a second choice of a local convenience store $(30 \%)$. In terms of preferred collection days, $76 \%$ of respondents would collect the missed deliveries from a local CDP closest to their home on a workday with the favored time being after working hours. Forty percent would consider walking to collect their packages, a similar result to that found in a study of Winchester residents in which $48 \%$ of 790 respondents stated that they would walk to their local CDP (24). Forty eight percent would choose to travel by car, $6 \%$ by bicycle and $4 \%$ would use the bus. The mean distance (home-to-CDP by road) of the $40 \%$ who said they would walk was $2.3 \mathrm{~km}$, based on the quickest route using Microsoft MapPoint. Clearly, walking could be a serious option, and this distance could be considerably less than $2.3 \mathrm{~km}$ if a crow-flight path could be taken using footpaths from the home.

\section{QUANTIFYING THE TRAVEL COSTS ACCRUED BY VARIOUS HOME DELIVERY METHODS}

Table 1 presents the changes in carrier (van-£) and customer (car- $£$ ) travelling costs incurred in a range of CDP home delivery scenarios, compared to the traditional delivery method (TRD3) where it was assumed that $50 \%$ of customers experiencing a failed first-time delivery would choose to collect the item from the carrier's depot. The changes in overall travelling costs (overall-£) are also presented. A negative percentage suggested that the CDP method reduced the amount of overall cost incurred. Table 1 was generated based on one van round and associated $10 \%, 20 \%, 30 \%, 40 \%$ and $50 \%$ first-time delivery failure rates in each scenario. For example, with $10 \%$ failures, the additional cost to the carrier for that van using railway station CDPs was $£ 32.3$ (\$47.9) (25).

The results (Table 1) suggested that diverting the failed first-time deliveries to the Local Collect post offices across West Sussex would be the most effective CDP option for the householder sample in terms of reducing their current travelling costs, (average 93\% reduction over a range of delivery failure rates that were modelled) compared to the traditional delivery method (TRD3). The CDP methods using the 12 Tesco Extra stores, 53 supermarkets from the ASDA, Morrison, Sainsbury's and Waitrose chains and the 46 railway stations were also able to reduce customer travelling costs compared to TRD3 (by between $61 \%$ and $81 \%$ ). The figures were calculated based on the average reductions on customer costs over a range of delivery failure rates modelled. Generally, reductions in 
householder travelling costs through using CDPs increased when the proportions of failed first-time deliveries increased (Figure 3). For example, under the scenario of a $50 \%$ first-time home delivery failure rate, the total customer travel cost under the traditional system (TRD3) was reduced by $£ 281.6$ (\$417.9) when using the 46 railways stations as CDPs to drop the failed packages. However, for the case where $10 \%$ of householders travelled to the carrier's depot to collect a failed delivery (TRD1), the CDP method was not necessarily beneficial in terms of customer travelling costs, depending on the CDP network used. Due to the locations of the 12 Tesco Extra stores in relation to the sample householders, the average distance to collect items from these CDPs was considerably greater.

From Table 1 and Figure 4, it can be seen that the carrier's travelling costs would generally increase until delivery failure rates reached $30 \%$ or over. At the $10 \%$ and $20 \%$ delivery failure rates, the carrier travelling costs were greater for all the CDP methods, indicating that the added travelling costs associated with visiting the CDPs were greater than those associated with making the redeliveries. This was due to the fact that the delivery round for the traditional method could be optimised to include the redeliveries, whereas for the CDP method, the visit to each of the CDPs had to be made after visiting all of the delivery addresses in its vicinity. This could introduce the possibility of the carrier's route containing an element of duplication as the vehicle doubled back on itself to visit a CDP. The overall observation is that the cost savings for the carrier of using the CDP method increased as the number of redeliveries to be made increased.

Despite this, the carrier would be likely to experience an overall service cost reduction when reduced call centre and depot handling charges were taken into consideration. Research has suggested that a carrier might incur a total cost of $£ 38.50$ (\$57.13) for each delivery failure (12) made up of:

- $\quad £ 4(\$ 5.9)$ for customer service costs

- $\quad £ 5$ (\$7.4) for handling stock/replacements/damages

- $£ 1.50$ (\$2.2) for one additional redelivery attempt

- $\quad £ 28$ (\$41.6) of other potential costs (e.g. answering customer enquiries; escalating complaints, handling claims, recalculating invoices, re-issuing invoices; customer attrition/loss; customer recruitment costs to replace those lost due to delivery problems).

By diverting the failed first-time delivery to the local CDP, the carrier could potentially negate these financial penalties whilst improving the customer experience and level of service offered. By also offering the CDP as a first-time delivery option, further reductions in carrier's delivery costs could be achievable due to the reduced number of addresses to be visited during the delivery round.

The combined carrier and householder travelling costs incurred through each of the CDP methods were compared to each traditional method (Figure 5). A general observation was that the CDP methods were able to reduce the total travelling costs compared to the current situation where $20 \%$ or more first-time deliveries fail. 
From Figure 5, the overall modeled costs were increased in some cases, for example, when the proportion of failed deliveries was relatively low and when the proportion of people traveling to the carrier's depot was also low (e.g. TRD1). Generally, however, the CDP method tended to reduce overall travelling costs, with the largest modeled saving of $59 \%$ being seen in the case where local post offices were used as CDPs, under the assumption that $50 \%$ of deliveries failed first time and that $50 \%$ of those would result in a customer collection from the carrier's depot. The CDP methods were most effective in terms of reducing overall travelling costs when: 1) 30\% or more customers who experienced a failed first-time home delivery would travel to the carrier's depot to retrieve goods; 2) $20 \%$ or more deliveries failed first time.

\section{QUANTIFYING THE ENVIRONMENTAL COSTS OF THE TRADITIONAL DELIVERY SYSTEM AGAINST THE CDP OPTIONS}

The distance driven, the types of vehicles, and the fuel used have a strong impact on traffic emissions. The potential environmental costs associated with the carrier and householder distances travelled in the traditional home delivery and the CDP methods were calculated based on the carbon emission factors for a typical diesel rigid delivery vehicle and a standard petrol family car (Table 2).

In the calculation, it was assumed that: 1) $30 \%$ of first-time home deliveries would fail; 2) $50 \%$ of customers would travel to the carrier's depot to collect the failed packages in the traditional system ( $87 \%$ by car); 3 ) $48 \%$ of householders would drive to the CDP in the various CDP scenarios. The carrier and householder emissions generated in the four CDP methods were quantified, and compared to the traditional method (Table 3).

It was found that the CDP delivery methods reduced emissions by between $48 \%$ and 58\% compared to the traditional delivery method, reflecting the fact that the overall driving distance was reduced when using CDPs.

Table 3 was generated based on the emission factors for the delivery vehicle and private car (Table 2), and their respective journey distances. The driving distance in Table 3 was the sum of the delivery vehicle and car kilometers. It was noted that the emission factor for a van and a car was $341 \mathrm{~g} / \mathrm{km}$ and $219 \mathrm{~g} / \mathrm{km}$, respectively.

\section{KEY FINDINGS AND SUMMARY}

The impacts of failed first-time home deliveries on additional carrier journeys (repeat deliveries), and customer trips (to retrieve goods from carrier depots) are of increasing concern to e-retailers and have been assessed in this research. The attended collection/delivery points (CDP) concept emerges as one of the solutions to deal with these first-time delivery failures, using a variety of outlets (e.g. convenience stores, petrol stations, post offices) as alternative addresses to receive deliveries.

Using a database of households from across West Sussex in the UK, this study has confirmed that certain benefits might accrue from using networks of Local Collect post offices, supermarkets and railway stations as CDPs, compared with the traditional 
delivery method where the carrier may make several redelivery attempts to the home with the customer making a personal trip to the carrier's depot in the event that these attempts also fail. A network of CDPs across West Sussex would function most effectively (in terms of reducing the overall travelling costs associated with handing failed first-time deliveries) when:

- The proportion of first-time home delivery failures is over $20 \%$;

- The proportion of customers travelling to the depot is over $30 \%$;

- Local Collect post offices are used as CDPs;

- Significant numbers of people would walk to their local CDP to collect a failed delivery as opposed to driving.

The best-case and worst-case scenarios for the use of CDPs are summarized in Table 4. CDPs situated at Local Collect post offices could achieve the largest reductions in overall travelling costs $(58.6 \%)$ compared to the traditional method. Using 12 Tesco Extra supermarkets as CDPs could be the most effective method of reducing carrier costs associated with making redelivery attempts ( $9.3 \%$ reduction in carrier's travelling costs). Across the 200 sample householders, the network of 139 Local Collect post offices were the most effective CDP option for receiving failed first-time home deliveries, reducing the current travelling costs (TRD3) by $93.2 \%$.

If the results from this study could be taken as representing typical working day operations for one carrier serving West Sussex, then over a 12-month period (312 working days, Monday to Saturday, 52 weeks a year), involving 62,400 deliveries, $£ 69,453$ $(\$ 103,068)$ might be incurred by the carrier (including first-time deliveries and some redeliveries) and $£ 65,330(\$ 96,950)$ by customers collecting failures from the carrier's depot. This is under the traditional home shopping scenario (TRD3) where it is assumed that $50 \%$ of customers experiencing a first-time home delivery failure will opt to travel to the carrier's depot to retrieve the item. The results suggested that the CDP methods could reduce the carrier travelling costs associated with redeliveries in a typical working day by between 4\% (where supermarkets across four chains were used as CDPs) and 9.3\% (Tesco Extra supermarkets were used as CDPs). Over a 12-month period, the carrier travelling cost could therefore be reduced by between $£ 2778(\$ 4,123)$ and $£ 6459$ $(\$ 9,585)$. The equivalent reductions in transport emissions were between 3.8 and 8.7 tonnes of $\mathrm{CO}_{2}$ as carbon per year. Similarly, the CDP delivery method was able to reduce the customer travelling costs by between $£ 39,851 \quad(\$ 59,139)$ and $£ 60,757(\$ 90,163)$ assuming that $50 \%$ of people travelled to the carrier's depot under scenario TRD3 to collect failed deliveries in person (reductions of 27.7 and 41.2 tonnes of $\mathrm{CO}_{2}$ as carbon per year).

The wider take-up of the CDP concept depends on the relationships between retailers, carriers and the various networks of often independently operated CDPs. If a major retailer were to offer CDP deliveries as part of their standard delivery service, or as an option for handling first-time failures, the network of outlets would have to be able to cope with the potential customer demand. At present, the current CDP networks in use are 
only designed to handle relatively small packages and any sudden increase in customer demand could adversely impact on the CDPs operations. In addition to capacity issues, any increase in demand for such a service could lead to congestion problems around the CDPs if customers chose to drive. Despite these issues, the increase in e-retailing will drive the need for more efficient and sustainable delivery options and CDPs could play an important role in bringing this about.

\section{REFERENCES}

1. Verdict (2006), Verdict on UK Home Delivery and Fulfillment 2006, Verdict Research, London

2. Verdict (2007), Verdict on e-Retail 2007, Verdict Research, London

3. Interactive Media in Retail Group (2008), IMRG e-Retail Sales Index Report, White paper on IMRG Forum. Available online at: http://www.imrg.org. Accessed $10 / 02 / 2008$.

4. Department for Transport (2005), Traffic Speeds in English Urban Areas: 2004, Transport Statistics Bulletin, National Statistics

5. Department for Transport (2005), Road Freight Statistics 2004. Available online at: http://www.dft.gov.uk. Accessed 05/01/2007.

6. Niles, J. S. (1994), Beyond telecommuting: a new paradigm for the effect of telecommunications on travel. Report DOE/ER-0626, prepared for the US Department of Energy, Office of Energy Research and Office of Scientific Computing. Available online at http://www.lbl.gov/ICSD/Niles/.Accessed 10/01/2006.

7. Lin II and Mahmassani, H. S. (2002), Can online grocers deliver? Some logistics considerations. Transportation Research Board, 81st annual meeting, January 7-11, 2002, Washington, D.C.

8. Siikavirta, H., Punakivi, M., Kärkkäinen, M. and Linnanen, L. (2003), Effects of e-commerce on greenhouse gas emissions. Journal of industrial ecology, Volume 6, No 2, pp. 83-97

9. Retail Logistics Task Force - Foresight (2000), @ Your Home: New Markets for Service and Delivery. Report to Retail Logistics Task Force of Foresight program, Department of Trade and Industry. Available online at http://www.foresight.gov.uk. Accessed 09/02/2005.

10. Interactive Media in Retail Group (2006), E-Christmas: online retailer results, Press 
Releases. Available online at: http://www.imrg.org/IMRG/press.nsf. Accessed $11 / 01 / 2007$.

11. McKinnon, A. C. and Tallam, D. (2003), Unattended delivery to the home: an assessment of the security implications, International Journal of Retail and Distribution Management, Vol. 31, No. 1, pp. 30-41

12. Interactive Media in Retail Group (2006), Valuing Home Delivery @ A Cost - Benefit Analysis, White paper on IMRG Forum. Available online at: http://www.imrg.org. Accessed 10/09/2007.

13. Giraffe Marketing, 2004, Available online at http://www.hippo-box.co.uk/. Accessed on 10 October 2005.

14. Bearbox (2004), Available online at http://www.bearbox.com/. Accessed on 6 October 2005.

15. ByBox (2004), Available online at http://www.bybox.com/. Accessed on 6 October 2005.

16. Chopra, S. and Meindl, P. (2003), Supply Chain Management, Upper Saddle River, NJ, Prentice Hall.

17. Department of Transport (2007), Transport Analysis Guidance, Available online at: www.webtag.org.uk. Accessed 10/09/2008.

18. The Guardian (2006), Tesco's market share reaches record high. June 2, 2006

19. Department for Transport (2007), National Travel Survey 2007, Transport Statistics Bulletin, National Statistics

20. Neighborhood Statistics (2005), Office of the Deputy Prime Minister (ODPM). Available online at www.communities.gov.uk/. Accessed 15/12/2007.

21. Department for Transport (2006), National Travel Survey 2006, http://www.dft.gov.uk. Accessed 05/01/2007.

22. Foley, P., Alfonso, X., Brown, K., Palmer, A., Lynch, D. and Jackson, M. (2003) Home shopping and home delivery in the UK 1995 to 2010. Final project report by De Montfort University and the Freight Transport Association for the Department for Transport.

23. Browne, M., Allen, J., Anderson, S., Jackson, M. (2001), Freight Transport Association - A Study for DTI, Overview of Home Deliveries in the UK. 
24. Cherrett, T and McLeod (2005), Missed another Home Delivery? The potential for Local Collect Points: University's Transport Studies Group annual conference, January 2005, Bristol.

25. UK Freight Transport Association (2007), http://www.fta.co.uk. Accessed 07/06/2007. 


\section{LIST OF FIGURES}

FIGURE 1: A map showing the 379 sample household origins (circles, white), 53 supermarkets (squares, red) from the Waitrose, Sainsbury, ASDA and Morrison chains, and 12 Tesco Extra (triangles, green) used as theoretical CDPs in West Sussex.

FIGURE 2: A map showing the 379 sample household origins (circles, white), 46 railway stations (squares, blue), and 139 Local Collect post offices (triangles, yellow) used as theoretical CDPs in West Sussex.

FIGURE 3: A map showing the 379 sample household origins (circles, white), 46 railway stations (squares, blue), and 139 Local Collect post offices (triangles, yellow) used as theoretical CDPs in West Sussex.

FIGURE 4: Carrier's travelling cost changes (\%) incurred by the CDP methods compared to the traditional method (TRD3), when the carrier delivered to 200 sample householders across West Sussex.

FIGURE 5.1: Overall travelling cost changes (\%) made by the CDP methods compared to the traditional method TRD1

FIGURE 5.2: Overall travelling cost changes (\%) made by the CDP methods compared to the traditional method TRD2

FIGURE 5.3: Overall travelling cost changes (\%) made by the CDP methods compared to the traditional method TRD3 


\section{LIST OF TABLES}

TABLE 1: Changes in customer and carrier travelling costs associated with various home delivery scenarios, compared to the traditional home delivery scenario (TRD3).

TABLE 2: Road transport emission factors, 2005.

TABLE 3: Road transport emissions generated from the home delivery operations serving 200 sample householders across West Sussex.

TABLE 4: Best case and worst case scenarios for the use of CDPs to re-direct failed first-time home deliveries (200 sample customers across West Sussex, with up to 8 delivery rounds). 


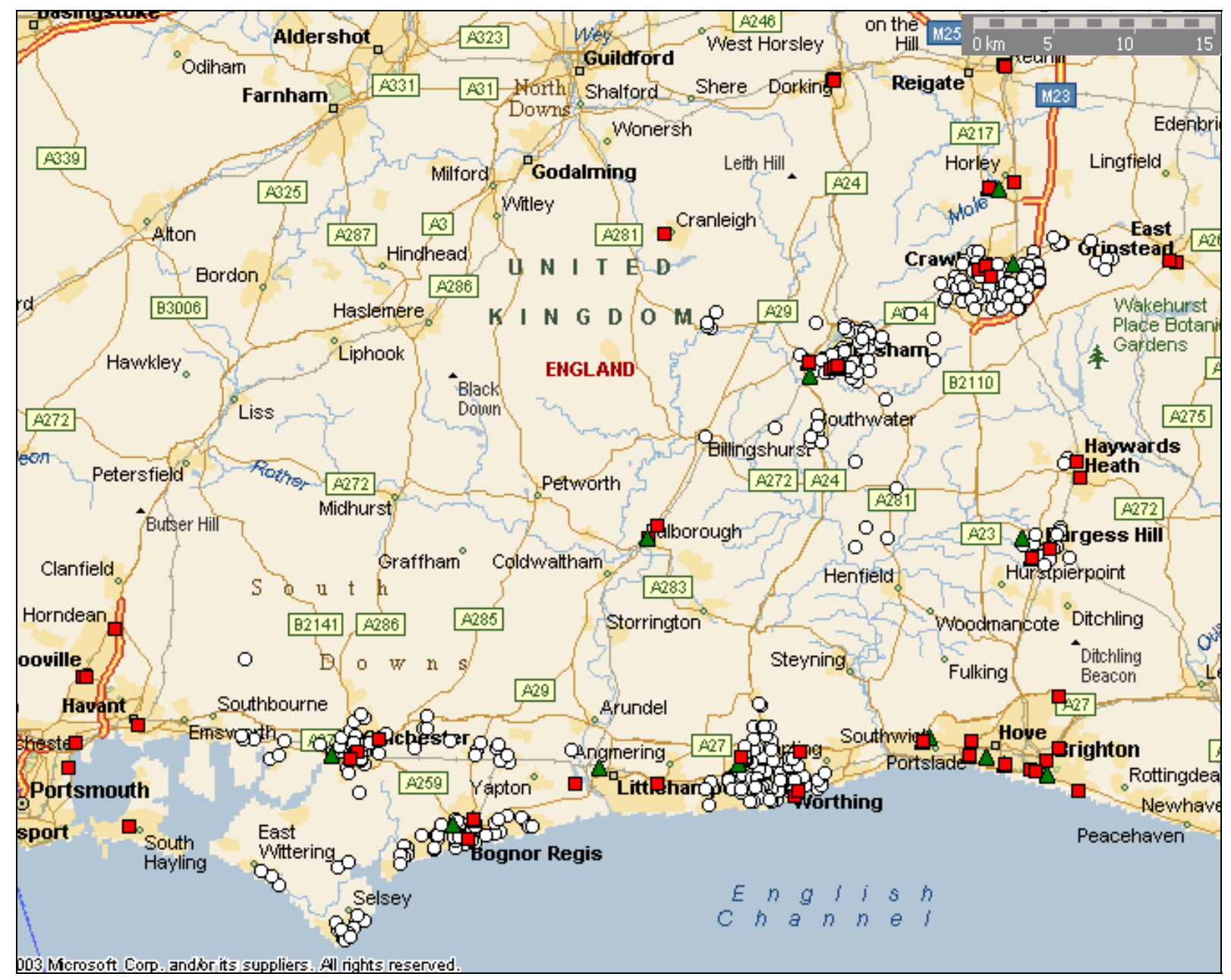

FIGURE 1 A map showing the 379 sample household origins (circles, white), 53 supermarkets (squares, red) from the Waitrose, Sainsbury, ASDA and Morrison chains, and 12 Tesco Extra (triangles, green) used as theoretical CDPs in West Sussex. 


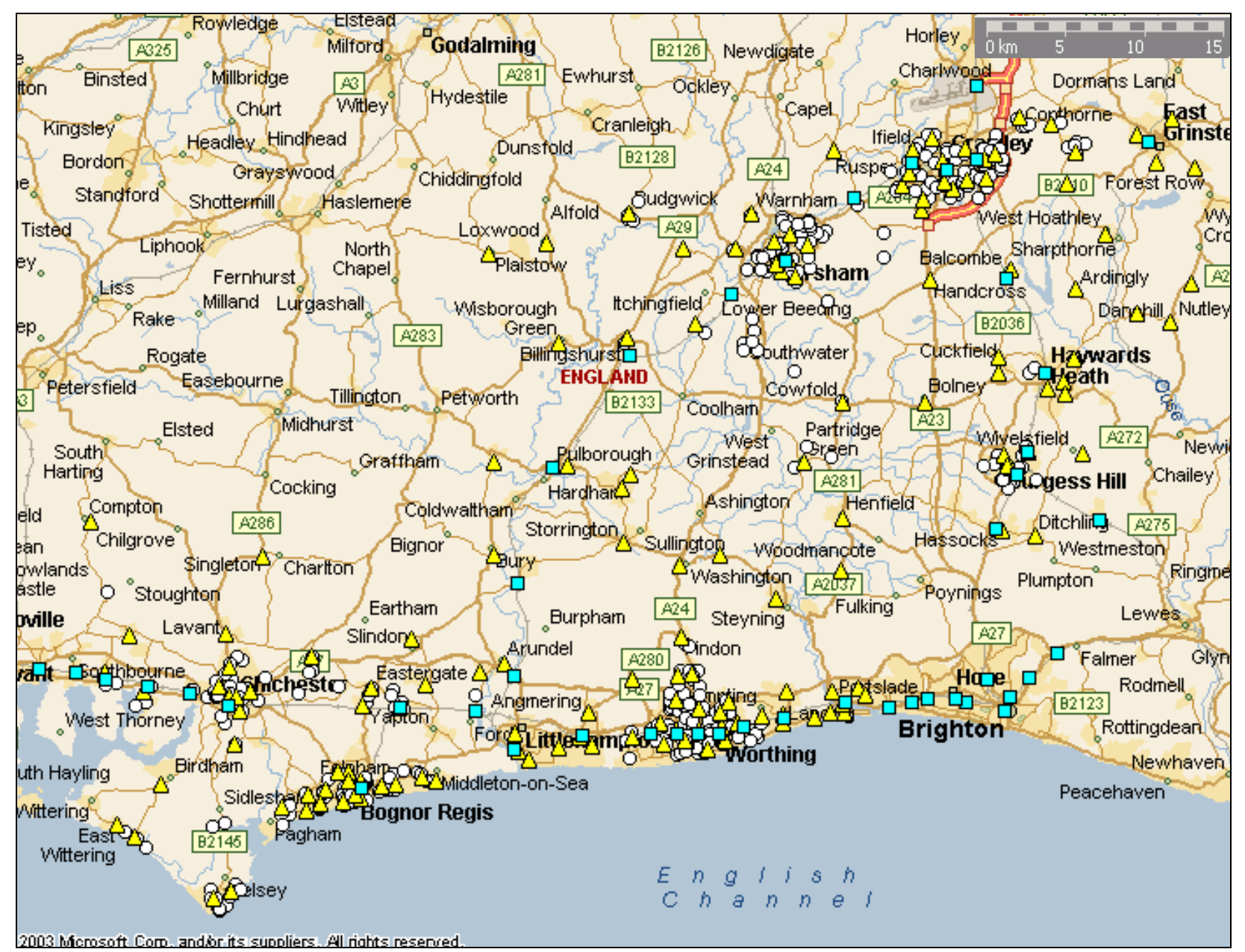

FIGURE 2 A map showing the 379 sample household origins (circles, white), 46 railway stations (squares, blue), and 139 Local Collect post offices (triangles, yellow) used as theoretical CDPs in West Sussex. 


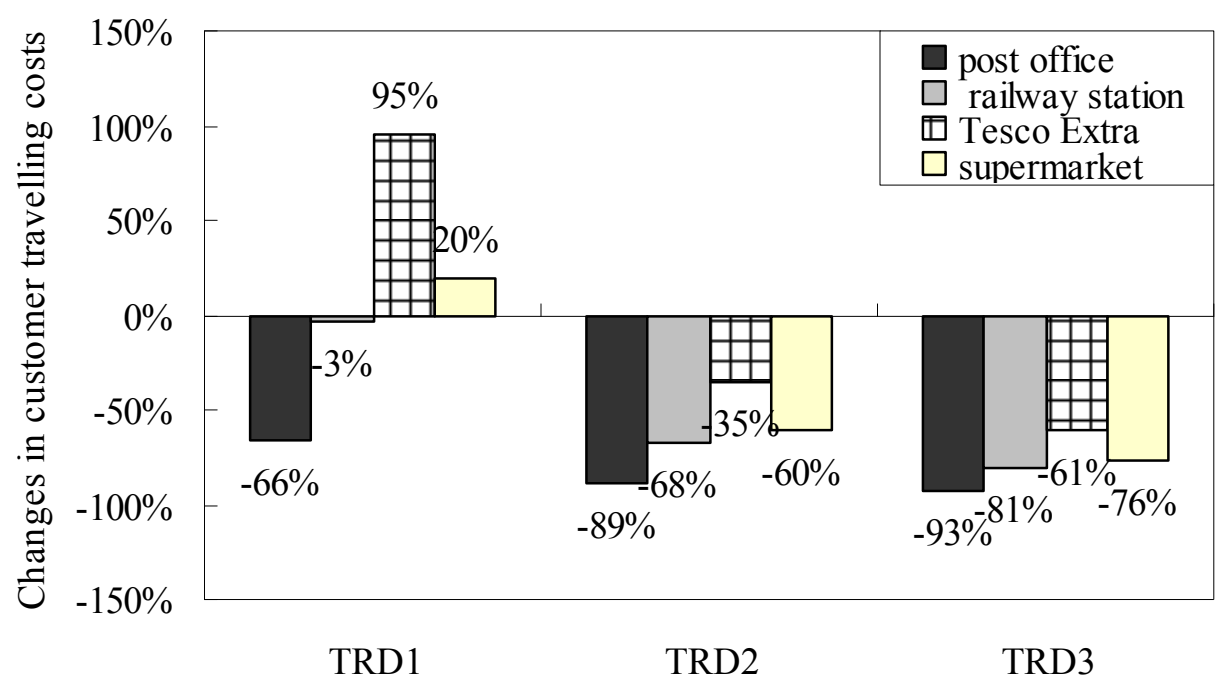

FIGURE 3 Customer's travelling cost changes (\%) made by the CDP methods compared to the existing methods, associated with carrier delivering to 200 sample householders across West Sussex. 


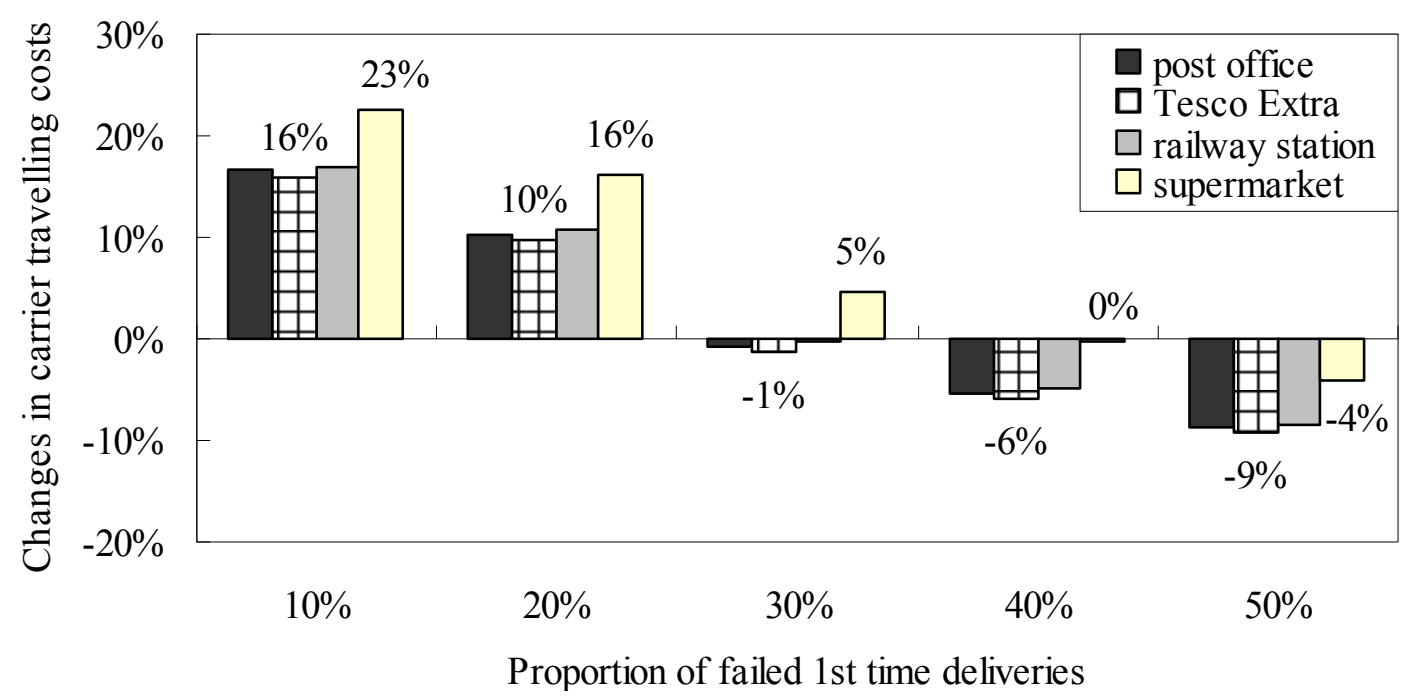

FIGURE 4 Carrier's travelling cost changes (\%) incurred by the CDP methods compared to the traditional method (TRD3), when the carrier delivered to 200 sample householders across West Sussex. 


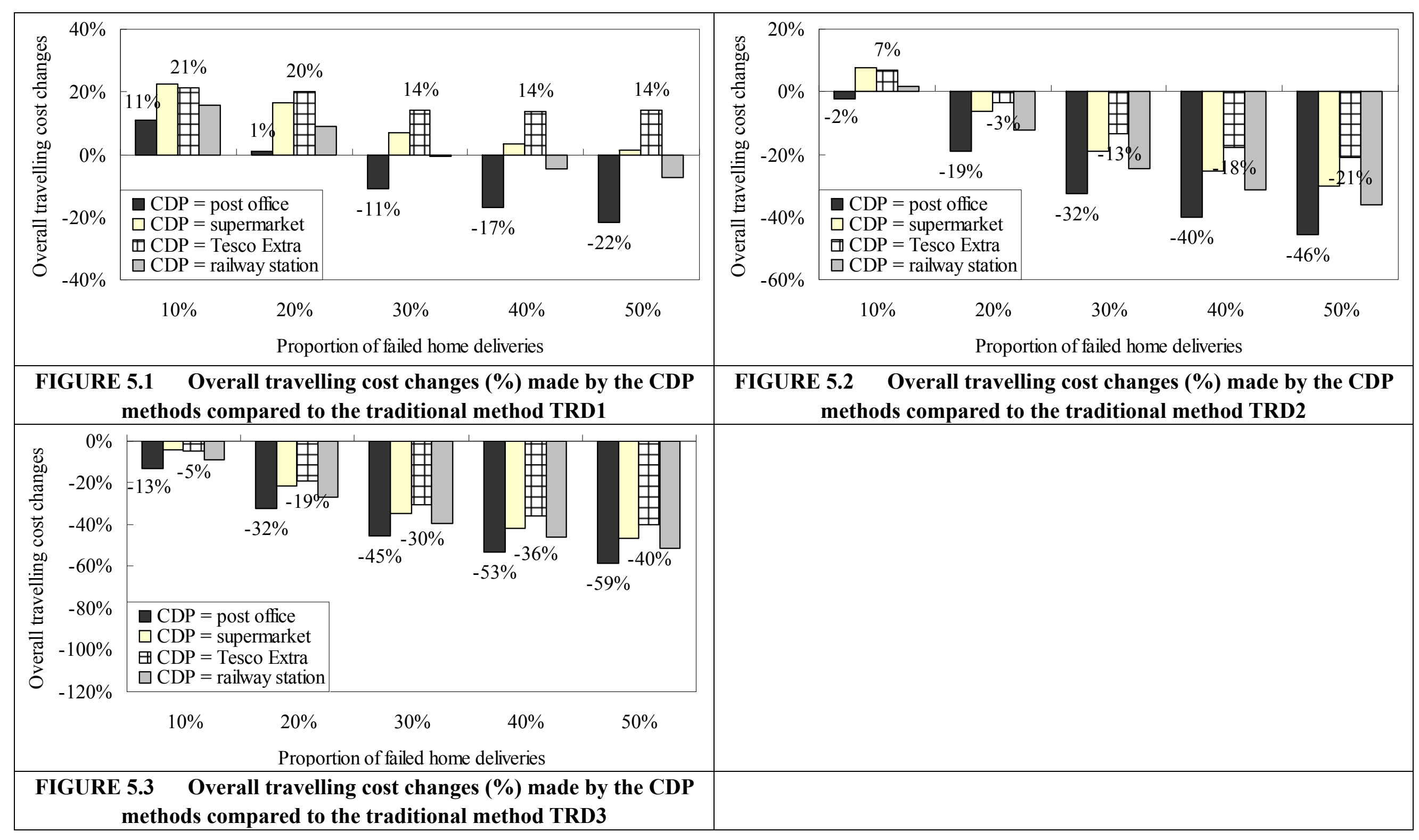


TABLE 1 Changes in customer and carrier travelling costs associated with various home delivery scenarios, compared to the traditional home delivery scenario (TRD3).

\begin{tabular}{|c|c|c|c|c|c|c|c|}
\hline \multirow{2}{*}{\multicolumn{2}{|c|}{ Scenarios }} & \multicolumn{6}{|c|}{ Changes in travel costs for householders and carrier } \\
\hline & & \multicolumn{2}{|c|}{ Van-cost $(\mathfrak{l})^{2}$} & \multicolumn{2}{|c|}{ Car-cost $(£)^{3}$} & \multicolumn{2}{|c|}{ Overall-cost $(\mathfrak{f})$} \\
\hline \multicolumn{8}{|c|}{$10 \%$ of first-time home deliveries failed: } \\
\hline CDP1 & $\mathrm{CDP}=$ railway station & 32.3 & $(17 \%)$ & -56.3 & $(-81 \%)$ & -24.0 & $(-9 \%)$ \\
\hline CDP2 & $\mathrm{CDP}=$ Tesco & 30.2 & $(16 \%)$ & -42.6 & $(-61 \%)$ & -12.4 & $(-5 \%)$ \\
\hline CDP3 & $\mathrm{CDP}=$ other supermarket & 42.9 & $(23 \%)$ & -53.1 & $(-76 \%)$ & -10.2 & $(-4 \%)$ \\
\hline CDP4 & $\mathrm{CDP}=$ Local Collect post office & 31.4 & $(17 \%)$ & -65.0 & $(-93 \%)$ & -33.6 & $(-13 \%)$ \\
\hline TRD1 & $\begin{array}{l}\text { Traditional delivery method } \\
(10 \% \text { travelling to the depot) }\end{array}$ & & & -55.8 & $(-80 \%)$ & -55.8 & $(-22 \%)$ \\
\hline TRD2 & $\begin{array}{l}\text { Traditional delivery method } \\
\text { (30\% travelling to the depot) }\end{array}$ & & & -27.9 & $(-40 \%)$ & -27.9 & $(-11 \%)$ \\
\hline TRD3 & $\begin{array}{l}\text { Traditional delivery method } \\
\text { (50\% travelling to the depot) }\end{array}$ & & & & & & \\
\hline \multicolumn{8}{|c|}{$20 \%$ of first-time home deliveries failed: } \\
\hline CDP1 & $\mathrm{CDP}=$ railway station & 21.5 & $(11 \%)$ & -112.6 & $(-81 \%)$ & -91.1 & $(-27 \%)$ \\
\hline $\mathrm{CDP} 2$ & $\mathrm{CDP}=$ Tesco & 19.4 & $(10 \%)$ & -85.1 & $(-61 \%)$ & -65.7 & $(-19 \%)$ \\
\hline CDP3 & $\mathrm{CDP}=$ other supermarket & 32.1 & $(16 \%)$ & -106.2 & $(-76 \%)$ & -74.1 & $(-22 \%)$ \\
\hline CDP4 & $\mathrm{CDP}=$ Local Collect post office & 20.6 & $(10 \%)$ & -130.0 & $(-93 \%)$ & -109.4 & $(-32 \%)$ \\
\hline TRD1 & $\begin{array}{l}\text { Traditional delivery method } \\
(10 \% \text { travelling to the depot) }\end{array}$ & & & -111.7 & $(-80 \%)$ & -55.8 & $(-16 \%)$ \\
\hline TRD2 & $\begin{array}{l}\text { Traditional delivery method } \\
\text { ( } 30 \% \text { travelling to the depot) }\end{array}$ & & & -55.8 & $(-40 \%)$ & -27.9 & $(-8 \%)$ \\
\hline TRD3 & $\begin{array}{l}\text { Traditional delivery method } \\
(50 \% \text { travelling to the depot) }\end{array}$ & & & & & & \\
\hline \multicolumn{8}{|c|}{$30 \%$ of first-time home deliveries failed: } \\
\hline CDP1 & $\mathrm{CDP}=$ railway station & -0.6 & $(0)$ & -169.0 & $(-81 \%)$ & -169.5 & $(-39 \%)$ \\
\hline $\mathrm{CDP} 2$ & $\mathrm{CDP}=$ Tesco & -2.7 & $(-1 \%)$ & -127.7 & $(-61 \%)$ & -130.4 & $(-30 \%)$ \\
\hline
\end{tabular}

\footnotetext{
2 the average values of time per LGV (van) was $£ 12.22$ (\$18.14) per hour

${ }^{3}$ the average values of time per private car was $£ 10.46(\$ 15.52)$ per hour
} 


\begin{tabular}{|c|c|c|c|c|c|c|c|c|}
\hline CDP3 & $\mathrm{CDP}=$ other supermarket & 10.0 & & $(5 \%)$ & -159.3 & $(-76 \%)$ & -149.3 & $(-35 \%)$ \\
\hline CDP4 & $\mathrm{CDP}=$ Local Collect post office & -1.5 & & $(-1 \%)$ & -195.0 & $(-93 \%)$ & -196.6 & $(-46 \%)$ \\
\hline TRD1 & $\begin{array}{l}\text { Traditional delivery method } \\
(10 \% \text { travelling to the depot) }\end{array}$ & & 0 & & -167.5 & $(-80 \%)$ & -167.5 & $(-39 \%)$ \\
\hline TRD2 & $\begin{array}{l}\text { Traditional delivery method } \\
(30 \% \text { travelling to the depot) }\end{array}$ & & 0 & & -83.8 & $(-40 \%)$ & -83.8 & $(-19 \%)$ \\
\hline TRD3 & $\begin{array}{l}\text { Traditional delivery method } \\
\text { ( } 50 \% \text { travelling to the depot) }\end{array}$ & & - & & & & & \\
\hline \multicolumn{9}{|c|}{$40 \%$ of first-time home deliveries failed: } \\
\hline CDP1 & $\mathrm{CDP}=$ railway station & -11.5 & & $(-5 \%)$ & -225.3 & $(-81 \%)$ & -236.7 & $(-46 \%)$ \\
\hline CDP2 & $\mathrm{CDP}=$ Tesco & -13.6 & & $(-6 \%)$ & -170.2 & $(-61 \%)$ & -183.8 & $(-36 \%)$ \\
\hline CDP3 & $\mathrm{CDP}=$ other supermarket & -0.9 & & $(0)$ & -212.5 & $(-76 \%)$ & -213.3 & $(-42 \%)$ \\
\hline CDP4 & $\mathrm{CDP}=$ Local Collect post office & -12.4 & & $(-5 \%)$ & -260.1 & $(-93 \%)$ & -272.5 & $(-53 \%)$ \\
\hline TRD1 & $\begin{array}{l}\text { Traditional delivery method } \\
\text { (10\% travelling to the depot) }\end{array}$ & & 0 & & -223.4 & $(-80 \%)$ & -223.4 & $(-44 \%)$ \\
\hline TRD2 & $\begin{array}{l}\text { Traditional delivery method } \\
\text { (30\% travelling to the depot) }\end{array}$ & & 0 & & -111.7 & $(-40 \%)$ & -111.7 & $(-22 \%)$ \\
\hline TRD3 & $\begin{array}{l}\text { Traditional delivery method } \\
\text { (50\% travelling to the depot) }\end{array}$ & & - & & & & & \\
\hline \multicolumn{9}{|c|}{$50 \%$ of first-time home deliveries failed: } \\
\hline CDP1 & $\mathrm{CDP}=$ railway station & -20.4 & & $(-8 \%)$ & -281.6 & $(-81 \%)$ & -302.0 & $(-51 \%)$ \\
\hline CDP2 & $\mathrm{CDP}=\mathrm{Tesco}$ & -22.6 & & $(-9 \%)$ & -212.8 & $(-61 \%)$ & -235.3 & $(-40 \%)$ \\
\hline CDP3 & $\mathrm{CDP}=$ other supermarket & -9.8 & & $(-4 \%)$ & -265.6 & $(-76 \%)$ & -275.4 & $(-47 \%)$ \\
\hline CDP4 & $\mathrm{CDP}=$ Local Collect post office & -21.3 & & $(-9 \%)$ & -325.1 & $(-93 \%)$ & -346.4 & $(-59 \%)$ \\
\hline TRD1 & $\begin{array}{l}\text { Traditional delivery method } \\
\text { (10\% travelling to the depot) }\end{array}$ & & 0 & & -279.2 & $(-80 \%)$ & -279.2 & $(-47 \%)$ \\
\hline TRD2 & $\begin{array}{l}\text { Traditional delivery method } \\
\text { ( } 30 \% \text { travelling to the depot) }\end{array}$ & & 0 & & -139.6 & $(-40 \%)$ & -139.6 & $(-24 \%)$ \\
\hline TRD3 & $\begin{array}{l}\text { Traditional delivery method } \\
\text { (50\% travelling to the depot) }\end{array}$ & & - & & & & & - \\
\hline
\end{tabular}

Under TRD3 it was assumed that 50\% of customers who experienced a first-time home delivery failure would travel to the carrier's depot to collect the item. 
TABLE 2 Road transport emission factors, 2005.

\begin{tabular}{|lccc|}
\hline Emission Factors & $\begin{array}{c}\text { Car } \\
\text { (Petrol Engined) }\end{array}$ & $\begin{array}{c}\text { Delivery Vehicle } \\
\text { (Diesel Engined) (LGV) }\end{array}$ \\
\hline $\mathrm{CO}_{2}$ & $(\mathrm{~g} / \mathrm{km})$ & 172 & 268 \\
$\mathrm{C}$ & $(\mathrm{g} / \mathrm{km})$ & 47 & 73 \\
\hline
\end{tabular}

Source: National Atmospheric Emissions Inventory (NAEI), UK, 2005. 
TABLE 3 Road transport emissions generated from the home delivery operations serving 200 sample householders across West Sussex $\left({ }^{4}\right)$.

\begin{tabular}{|lccc|}
\hline Delivery Model & $\begin{array}{c}\text { Driving } \\
\text { distance } \\
(\mathbf{k m})\end{array}$ & $\begin{array}{c}\text { Emissions } \\
\text { (kg of carbon } \\
\text { equivalent) }\end{array}$ & $\begin{array}{c}\text { Emission reduction } \\
\text { compared with TRD3 }\end{array}$ \\
\hline CDP = Local Collect Post office & 939.7 & 309.0 & $-40.0 \%$ \\
CDP = Supermarket & 1150.1 & 366.0 & $-29.0 \%$ \\
CDP = Tesco Extra & 1246.0 & 381.1 & $-26.1 \%$ \\
CDP = Railway station & 1063.8 & 341.8 & $-33.7 \%$ \\
Traditional method & 1846 & 515.4 & - \\
\hline
\end{tabular}

\footnotetext{
${ }^{4}$ up to 8 delivery rounds, $30 \%$ failed first-time deliveries, all householders experiencing failed deliveries in the traditional system would travel to the carrier's depot to collect the failed items)
} 
TABLE 4 Best case and worst case scenarios for the use of CDPs to re-direct failed first-time home deliveries (200 sample customers across West Sussex, with up to 8 delivery rounds).

\begin{tabular}{|c|c|c|}
\hline 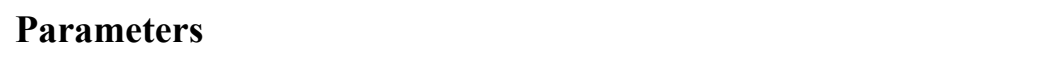 & Best case & Worst case \\
\hline proportion of failed first time deliveries & $50 \%$ & $10 \%$ \\
\hline $\begin{array}{l}\text { proportion of people travelling to depot under the traditional } \\
\text { system }\end{array}$ & $50 \%$ & $10 \%$ \\
\hline \multicolumn{3}{|l|}{ Overall Travelling Costs Changes } \\
\hline $\mathrm{CDP}=$ Railway stations & $-51.1 \%$ & $15.6 \%$ \\
\hline $\mathrm{CDP}=$ Other supermarkets & $-46.6 \%$ & $22.4 \%$ \\
\hline $\mathrm{CDP}=$ Tesco & $-39.8 \%$ & $21.3 \%$ \\
\hline $\mathrm{CDP}=$ Post offices & $-58.6 \%$ & $10.9 \%$ \\
\hline \multicolumn{3}{|l|}{ Carrier Travelling Cost Changes } \\
\hline $\mathrm{CDP}=$ Railway stations & $-8.4 \%$ & $17.0 \%$ \\
\hline $\mathrm{CDP}=$ Other supermarkets & $-4.0 \%$ & $22.6 \%$ \\
\hline $\mathrm{CDP}=$ Tesco & $-9.3 \%$ & $15.9 \%$ \\
\hline $\mathrm{CDP}=$ Post offices & $-8.8 \%$ & $16.5 \%$ \\
\hline \multicolumn{3}{|l|}{ Customer Travelling Cost Changes } \\
\hline $\mathrm{CDP}=$ Railway stations & $-80.7 \%$ & $-3.5 \%$ \\
\hline $\mathrm{CDP}=$ Other supermarkets & $-76.1 \%$ & $19.5 \%$ \\
\hline $\mathrm{CDP}=$ Tesco & $-61.0 \%$ & $95.2 \%$ \\
\hline $\mathrm{CDP}=$ Post offices & $-93.2 \%$ & $-65.7 \%$ \\
\hline
\end{tabular}

